\title{
Meropenem Target Attainment and Population Pharmacokinetics in Critically III Septic Patients with Preserved or Increased Renal Function
}

\author{
Matthias Gijsen (D) ${ }^{1,2}$ \\ Omar Elkayal' \\ Pieter Annaert (D) 1,3 \\ Ruth Van Daele ${ }^{1,2}$ \\ Philippe Meersseman ${ }^{4}$ \\ Yves Debaveye ${ }^{4}$ \\ Joost Wauters ${ }^{4}$ \\ Erwin Dreesen' \\ Isabel Spriet ${ }^{1,2}$
}

'Department of Pharmaceutical and Pharmacological Sciences, KU Leuven, Leuven, Belgium; ${ }^{2}$ Pharmacy Department, University Hospitals Leuven, Leuven, Belgium; ${ }^{3}$ BioNotus, Niel, Belgium;

${ }^{4}$ Department of Cellular and Molecular Medicine, KU Leuven, Leuven, Belgium

Correspondence: Matthias Gijsen Pharmacy Department, University Hospitals Leuven, Herestraat 49, Leuven, 3000 , Belgium

Tel +32 I6 340087

Fax +32 16 343080

Email mathias.gijsen@uzleuven.be
Purpose: Critically ill patients with preserved or increased renal function have been shown to be at risk of underexposure to meropenem. Although many meropenem population pharmacokinetic (PK) models have been published, there is no large prospective population PK study with rich sampling focusing on patients most at risk of suboptimal pharmacokinetic/pharmacodynamic (PK/PD) target attainment. Therefore, the aim of the present study was to evaluate PK/PD target attainment and to perform a thorough covariate screening using population PK modelling of meropenem in septic patients with preserved or increased renal function.

Patients and Methods: A single-centre prospective observational PK study was performed in the intensive care unit (ICU) of the University Hospitals Leuven. Patients with severe sepsis or septic shock and treated with meropenem in the ICU were screened for inclusion. Patients were excluded if they received renal replacement therapy or had an estimated glomerular filtration rate according to the Chronic Kidney Disease Epidemiology collaboration equation $<70 \mathrm{~mL} / \mathrm{min} / 1.73 \mathrm{~m}^{2}$ on the day of PK sampling. Successful PK/PD target attainment was defined as an unbound meropenem trough concentration above $2 \mathrm{mg} / \mathrm{L}$ or $8 \mathrm{mg} / \mathrm{L}$. Population PK modelling was performed with NONMEM7.4.

Results: In total, 58 patients were included, contributing 345 plasma samples over 70 dosing intervals. The $2 \mathrm{mg} / \mathrm{L}$ and $8 \mathrm{mg} / \mathrm{L}$ targets were successfully attained in $46 \%$ and $11 \%$ of all dosing intervals, respectively. A two-compartment population PK model with linear elimination and interindividual variability on clearance best described meropenem PK. The estimated creatinine clearance according to the Cockcroft-Gault equation was the only covariate retained during population $\mathrm{PK}$ analysis.

Conclusion: This study provided detailed insight into meropenem PK in critically ill patients with preserved or increased renal function. We observed poor PK/PD target attainment, for which renal function was the only significant covariate.

Trial Registration: This study is registered at ClinicalTrials.gov (NCT03560557).

Keywords: intensive care, $\mathrm{PK} / \mathrm{PD}$, exposure, dose optimization, augmented renal clearance

\section{Introduction}

Severe bacterial infections frequently lead to sepsis and septic shock, which are common causes of death in the intensive care unit (ICU). Worldwide, patients with sepsis reach unacceptably high mortality rates of $25 \%$ and even more in patients with septic shock. ${ }^{1,2}$ It is generally accepted that "early goal directed antimicrobial therapy", referring to the initiation of adequate antimicrobial agents in the right dose as early as possible, significantly decreases mortality rates and has the 
potential to avoid emerging resistance in patients with severe sepsis and septic shock. ${ }^{3,4}$ However, until control of the inflammatory reaction has been attained, antimicrobial pharmacokinetics (PK) are extremely altered due to pathophysiological disturbances associated with critical illness. Augmented renal clearance (ARC) and increased volume of distribution may lead to subtherapeutic antimicrobial exposure, resulting in therapeutic failure and induction of antimicrobial resistance. ${ }^{5-9}$

Meropenem is a broad-spectrum beta-lactam antibiotic used to treat life-threatening infections in the ICU. It is commonly used in the empiric therapy of sepsis or complicated infections and in the targeted therapy of multidrug-resistant gram-negative pathogens. ${ }^{10}$ Meropenem is a time-dependent bactericidal antibiotic. In critically ill patients, unbound concentrations exceeding 1- to 4-fold the minimal inhibitory concentration throughout the whole dosing interval $\left(100 \% f \mathrm{~T}_{>1-4 \mathrm{xMIC}}\right)$ are recommended for optimal bacterial killing and to avoid emergence of antimicrobial resistance. ${ }^{9,11}$ Several studies have shown that conventional meropenem dosing regimens may lead to unacceptable $\mathrm{PK} /$ pharmacodynamic (PK/PD) target attainment in critically ill patients. ARC, but also preserved renal function, has been identified as major causes for underexposure. $^{9,12-15}$ This is not surprising as meropenem shows major renal clearance (approx. 70\%). ${ }^{16}$ Alternative dosing strategies, such as extended or continuous infusion, have been suggested. ${ }^{17}$ Nevertheless, conventional dosing is still common as there is currently no consensus on meropenem dosing in critically ill patients and therapeutic drug monitoring for meropenem is still not implemented in most ICUs. ${ }^{18,19}$ Several population PK (population PK) models have been published in an attempt to describe and predict meropenem exposure in critically ill patients. Recently, Dhaese et al have shown that there is substantial variability in the predictive performance of these population PK models. ${ }^{17}$ This could be because these models were developed in rather small and selected populations (9-34 patients). Recently, a few population PK models have been developed in larger ICU populations, although these were based on data from retrospective studies ${ }^{20,21}$ or included mainly patients with impaired renal function. ${ }^{13}$

Therefore, the aim of the present study was to prospectively evaluate PK/PD target attainment in a larger study population with sepsis and preserved or increased renal function and to perform a thorough covariate screening using population PK modelling of meropenem.

\section{Materials and Methods}

\section{Study Design and Setting}

A prospective single-centre observational cohort study was carried out on the ICUs of a tertiary-care academic hospital (University Hospitals Leuven, Leuven, Belgium) between October 2013 and October 2017. The study was conducted in accordance with the Declaration of Helsinki, and the study protocol was approved by the Ethics Committee Research UZ/KU Leuven (S54511). Written informed consent was obtained from the patient or the closest relative before inclusion in this study. All adult patients admitted to the ICU, treated with meropenem and having severe sepsis or septic shock (as defined according to the definitions applicable at the time of the study; cf. File S1) ${ }^{22,23}$ at the start of meropenem therapy were screened for inclusion. Exclusion criteria were pregnancy, do-not-resuscitate order, extracorporeal membrane oxygenation, renal replacement therapy, decreased renal function defined as an estimated glomerular filtration rate according to the Chronic Kidney Disease Epidemiology Collaboration equation (eGFR CKD-EPI $)<70 \mathrm{~mL} / \mathrm{min} /$ $1.73 \mathrm{~m}^{2}$ on the day of PK sampling.

In the present study, ARC was defined as a measured urinary creatinine clearance by $24 \mathrm{~h}$ urine collection $\left(\mathrm{mCrCl}_{24 \mathrm{~h}}\right) \geq 130 \mathrm{~mL} / \mathrm{min} / 1.73 \mathrm{~m}^{2}$, according to the consensus in the current literature. ${ }^{24}$

\section{Study Protocol}

The study protocol has been previously published. ${ }^{25}$ In short, blood samples were collected on an early day (day $2 \pm 1$ ) and/or a later day (day $5 \pm 1$ ) of meropenem therapy, depending on practical feasibility. Sampling was performed around one dosing interval at -15 minutes (predose), 30 (at time of infusion stop), 120, and 240 minutes after the start of the infusion, and 15 minutes before the start of the next infusion (pre-dose). Meropenem was administered as an intermittent infusion and dosing was at the discretion of the treating physician. As reported previously, during the first year of the study, plasma samples were stored at $-20^{\circ} \mathrm{C}$ until quantification. ${ }^{25}$ However, new insights revealed significant degradation during longterm storage of meropenem at $-20^{\circ} \mathrm{C} .^{26,27}$ Subsequently, from the beginning of the second year of the study on, all plasma samples were stored at $-80^{\circ} \mathrm{C}$ within 24 hours after collection, until quantification within one year. For the plasma samples that were stored at $-20^{\circ} \mathrm{C}$ for maximum one year, meropenem concentrations were corrected using 
a validated degradation model. ${ }^{28}$ Total meropenem concentrations were treated as unbound concentrations due to negligible plasma protein binding of meropenem (ie, $2 \%) .{ }^{16}$ Meropenem plasma concentrations were quantified using a validated ultra-performance liquid chromatography method coupled with tandem mass spectrometry, which has been described in detail elsewhere. ${ }^{25}$

\section{PK/PD Target Attainment}

Based on current recommendations for therapeutic drug monitoring of meropenem in the ICU, PK/PD target attainment was defined as $100 \% f \mathrm{~T}_{>\mathrm{MIC}}{ }^{11}$ and $100 \% f \mathrm{~T}_{>4 \times \mathrm{MIC}}{ }^{9}$ The $100 \% f \mathrm{~T}_{>\text {MIC }}$ and $100 \% f \mathrm{~T}_{>4 \times \mathrm{MIC}}$ are recommended for maximal bacterial killing ${ }^{11}$ and optimal clinical outcome while avoiding emerging resistance ${ }^{9}$ with beta-lactam antibiotics in critically ill patients, respectively. As no exact minimal inhibitory concentration values were available, to calculate PK/PD target attainment, the minimal inhibitory concentration clinical breakpoint for susceptibility of Enterobacterales to meropenem (ie, $2 \mathrm{mg} / \mathrm{L}$ ) - as recommended by the European Committee on Antimicrobial Susceptibility Testing - was used. ${ }^{29}$ Thus, PK/PD target attainment was defined as unbound concentrations exceeding $2 \mathrm{mg} / \mathrm{L}$ or $8 \mathrm{mg} / \mathrm{L}$ throughout the whole dosing interval, corresponding to $100 \% f \mathrm{~T}_{>\mathrm{MIC}}$ and $100 \%$ $f \mathrm{~T}_{>4 \mathrm{xMIC}}$, respectively.

\section{Population PK Modelling}

Population PK analysis was performed using NONMEM (version 7.4; ICON Development Solutions, Gaithersburg, MD, USA), with a GNU Fortran 95 compiler and the Perlspeaks-NONMEM (PsN; version 4.7.0) toolkit on the interface software Pirana (version 2.9.7; Certara, Inc., Princeton, NJ, USA).

First-order conditional estimation with interaction and differential equation solver ADVAN 13 was used for parameter estimation. The precision of the parameter estimates was evaluated based on the root squared error. A base model was developed by evaluating different structural models with varying numbers of compartments (one, two and three compartments) and the presence or absence of interindividual and inter-occasion variability in the PK parameters. An occasion was defined as a dosing interval. Individual PK parameters were assumed to be ln-normally distributed using an exponential function. For example, the clearance (CL) parametrisation followed this equation:

$$
\mathrm{CL}_{i}=\mathrm{TVCL} \times \exp \left(\eta_{i}\right) \text { with } \eta_{i} \infty \mathrm{N}\left(0, \omega^{2}\right)
$$

with $\mathrm{CL}_{i}$ the clearance of subject $i$, TVCL the typical population value of the clearance, $\eta_{i}$ the individual subject's deviation from the typical value, and $\omega^{2}$ is the variance of inter-subject variability. Allometric scaling was tested with exponents of 0.75 and 1 on $C L$ and volume of distribution, respectively.

The base model (including the number of compartments) was selected by objective function value comparisons (difference $\geq 3.84$ points; $\mathrm{P} \leq 0.05$ ), the condition number $(<1000)$, physiological plausibility and precision of parameter estimates, and goodness-of-fit plots. A final model, including covariate effects, was built via a two-way stepwise covariate modelling procedure (forward inclusion $\alpha=0.010$; backward elimination $\alpha=0.001$ ). The tested covariates were selected based on previously published (population) PK studies of meropenem and expert consensus, and included age, body weight, body mass index, ideal body weight, adjusted body weight, serum creatinine, estimated creatinine clearance according to the CockcroftGault equation $\left(\mathrm{eCrCl}_{\mathrm{CG}}\right)$, eGFR according to the Modification of Diet in Renal Disease equation, eGFR ${ }_{\text {CKD-EPI }}, \mathrm{mCrCl}_{24 \mathrm{~h}}$, probability of $\mathrm{ARC}$ on the day of sampling according to the ARC predictor, ${ }^{30}$ fluid balance, and Acute Physiology and Chronic Health Evaluation II, and Sequential Organ Failure Assessment scores.

The final model was evaluated using a prediction-corrected visual predictive check $(n=1000)$. Good predictive ability of the final model was defined as median values and $95 \%$ confidence intervals of the prediction-corrected observed data falling within the $95 \%$ prediction intervals of the model, which was illustrated using this predictioncorrected visual predictive check. Furthermore, bootstrapping was performed to obtain nonparametric estimates of uncertainty in parameter estimates ( $\mathrm{n}=2000$ bootstraps).

The NONMEM control stream of the final population PK model is available in File S2.

\section{Statistical Analysis Not Related to Population PK Modelling}

The results are expressed as median [interquartile range]. Differences in meropenem trough concentrations or PK/ PD target attainment were evaluated using an unpaired Student's $t$-test or a Chi-square test, respectively. All analyses other than the population PK were performed in $\mathrm{R}$ (version 4.0.0, R Core Team, Vienna, Austria) in the 
RStudio integrated development environment (version 1.3; RStudio, Inc., Boston, MA, USA) using the tidyverse ${ }^{31}$ collection of packages and ggplot2. ${ }^{32}$

\section{Results}

\section{Patient Characteristics}

In total, 58 patients were included, contributing 345 plasma samples over 70 dosing intervals, as shown in the inclusion flow diagram (Supplementary Figure 1). The main clinical characteristics are shown in Table 1. Sixty-nine percent of our cohort were male patients. Age and weight were 63 years $[55 ; 68]$ and $70 \mathrm{~kg}[60$; 79], respectively. The Acute Physiology and Chronic Health Evaluation II and Sequential Organ Failure Assessment scores on admission were $20[16 ; 25]$ and $9[7 ; 10]$, respectively. Most patients (83\%) were sampled on an early day. Twelve patients were sampled on an early and a late day during meropenem treatment (Table 1). The $\mathrm{mCrCl}_{24 \mathrm{~h}}$ was $84 \mathrm{~mL} / \mathrm{min} / 1.73 \mathrm{~m}^{2}$ [64; 119] and $109 \mathrm{~mL} / \mathrm{min} / 1.73 \mathrm{~m}^{2}[75 ; 136]$ on early and late sampling days, respectively. Overall, the $\mathrm{mCrCl}_{24 \mathrm{~h}}$ was 88 [69; 128], and ARC was present on 16/66 (24.2\%) dosing intervals for which $\mathrm{mCrCl}_{24 \mathrm{~h}}$ was available. On most sampling days (64\%), patients received meropenem $1000 \mathrm{mg} \mathrm{q} 8 \mathrm{~h}$. The remaining patients received meropenem $2000 \mathrm{mg}$ q $8 \mathrm{~h}$, except for two sampling days (500 mg q8h). All patients received meropenem as a short infusion over 30 minutes. The infection focus was mainly respiratory (72\%). Forty-seven (81\%) patients survived their ICU stay.

\section{PK/PD Target Attainment}

The median meropenem unbound trough concentration was $1.83 \mathrm{mg} / \mathrm{L}[0.73 ; 4.85]$. Trough concentrations were $1.92 \mathrm{mg} / \mathrm{L}[0.82 ; 4.37]$ and $1.14 \mathrm{mg} / \mathrm{L}[0.58 ; 2.96]$ on early and late sampling days. There was no significant difference in trough concentrations between early vs late sampling days $(p=0.88)$. No concentrations were below the lower limit of quantification $(0.09 \mathrm{mg} / \mathrm{L})$. The $100 \%$ $f \mathrm{~T}_{>\mathrm{MIC}}$ and $100 \% f \mathrm{~T}_{>4 \mathrm{xMIC}} \mathrm{PK} / \mathrm{PD}$ targets - considering a minimal inhibitory concentration of $2 \mathrm{mg} / \mathrm{L}$ - were successfully attained on $46 \%$ and $11 \%$ of all sampling days, respectively (Table 1). Although there was a slight decrease in attainment of the $100 \% f \mathrm{~T}_{>\mathrm{MIC}}$ target, there was no significant difference in target attainment between early vs late sampling days $(p=0.42)$, as illustrated in Figure 1.

\section{Population Pharmacokinetic Modelling}

A two-compartment population PK model with linear elimination best described the PK of meropenem. Interoccasion variability in PK could not be identified. IIV was identified on clearance $(57.8 \%$ coefficient of variation $[\mathrm{CV}]$ ), volume of the central compartment $(57 \% \mathrm{CV})$, and volume of the peripheral compartment $(74.4 \% \mathrm{CV})$. Allometric scaling was not retained since it did not improve the base model (goodness-of-fit plots of the base model are shown in Supplementary Figure 2). After performing stepwise covariate modelling, eCrCl $\mathrm{CG}$ was the only covariate withheld in our final model, explaining $18 \%$ of the IIV on CL. The $\mathrm{eCrCl}_{\mathrm{CG}}$ performed significantly better than any other covariate. Equation 2 shows how meropenem clearance of patient $i$ increases with $\mathrm{eCrCl}_{\mathrm{CG}}$ :

$$
\mathrm{CL}_{i}=13.7 \frac{\mathrm{L}}{\mathrm{h}} \times\left(\frac{\mathrm{eCrCl}_{\mathrm{CG}}}{111.7 \mathrm{~mL} / \mathrm{min}}\right)^{0.725}
$$

Parameter estimates of the final model are shown in Table 2. Goodness-of-fit plots showed that the final model adequately described the observed data (Supplementary Figure 3). A prediction-corrected visual predictive check showed the good predictive ability of our model, where the median values and the $95 \%$ confidence intervals of the prediction-corrected observed data fell within the $95 \%$ prediction intervals of the model (Figure 2). Median values of the nonparametric bootstrap replicates were in good agreement with point estimates (Table 2).

\section{Discussion}

In this study, we showed poor PK/PD target attainment of meropenem in critically ill patients with preserved or increased renal function. Solely renal function was retained as a significant predictor of meropenem exposure during population PK analysis.

Only half of the patients achieved the most conservative of both predefined PK/PD targets. Target attainment was equally low on early vs late sampling days, despite a slight increase in renal function. A previously published study investigating PK changes during meropenem therapy in septic patients also found no significant difference in target attainment and PK between early and late sampling days, despite increased renal function. ${ }^{33}$ Interestingly, both in the latter and in the present study, there is a trend towards lower trough concentrations - and target 
Table I Clinical Characteristics

\begin{tabular}{|c|c|c|c|}
\hline Parameter & Overall & On Early Sampling Day & On Late Sampling Day \\
\hline Number of patients, $n(\%){ }^{a}$ & $58(100)$ & $48(83)$ & $22(38)$ \\
\hline \multicolumn{4}{|l|}{ Demographics } \\
\hline Sex, male, n (\%) & $40(69)$ & & \\
\hline Age, median [IQR], years & $63[55 ; 68]$ & & \\
\hline Body weight, median [IQR], $\mathrm{kg}$ & $70[60 ; 79]$ & & \\
\hline ICU mortality, n (\%) & II (19) & & \\
\hline \multicolumn{4}{|l|}{ Severity of infection, $n(\%)$} \\
\hline Severe sepsis & $26(45)$ & & \\
\hline Septic shock & $32(55)$ & & \\
\hline \multicolumn{4}{|l|}{ Site of infection, $\mathrm{n}(\%)$} \\
\hline Respiratory & $42(72)$ & & \\
\hline Gastro-intestinal & $6(10)$ & & \\
\hline Hepatic & $3(5)$ & & \\
\hline Skin and soft tissue & $3(5)$ & & \\
\hline Other & $2(3)$ & & \\
\hline Unknown & $2(3)$ & & \\
\hline Days meropenem therapy until start sampling, median [IQR], days & & I [I; I.7] & $4.3[4 ; 4.7]$ \\
\hline Days ICU until start sampling, median [IQR], days & & $3[1.5 ; 9.4]$ & $6[4.1 ; 12.9]$ \\
\hline Daily meropenem dose, median [IQR], mg/day & & $3000[3000 ; 6000]$ & $3000[3000 ; 6000]$ \\
\hline Mechanical ventilation, $\mathrm{n}(\%)$ & & $35(73)$ & $13(59)$ \\
\hline Vasopressor therapy, n (\%) & & $27(56)$ & $10(45)$ \\
\hline \multicolumn{4}{|l|}{ Clinical scores } \\
\hline SOFA score on ICU admission, median [IQR] & $9[7 ; 10]$ & & \\
\hline SOFA score on day of sampling, median [IQR] & & $9[6 ; 10]$ & $7[5 ; 10]$ \\
\hline APACHE II score, median [IQR] & $20[16 ; 25]$ & & \\
\hline \multicolumn{4}{|l|}{ Biochemical parameters } \\
\hline $\mathrm{mCrCl} 24 \mathrm{~h}$, median [IQR], $\mathrm{mL} / \mathrm{min} / 1.73 \mathrm{~m}^{2 \mathrm{~b}}$ & & $84[64 ; 119]$ & $109[75 ; 136]$ \\
\hline $\mathrm{eGFR}_{\mathrm{CKD} \text {-EPI}}$, median [IQR], $\mathrm{mL} / \mathrm{min} / 1.73 \mathrm{~m}^{2}$ & & $104[91 ; 119]$ & $112[101 ; 119]$ \\
\hline \multicolumn{4}{|l|}{ Sampling } \\
\hline Unbound meropenem pre-dose concentration $\geq 2 \mathrm{mg} / \mathrm{L}^{\mathrm{c}}, \mathrm{n}$ (\%) & $32 / 70(46)$ & $24 / 48(50)$ & $8 / 22(36)$ \\
\hline Unbound meropenem pre-dose concentration $\geq 8 \mathrm{mg} / \mathrm{L}^{\mathrm{c}}, \mathrm{n}(\%)$ & $8 / 70(I I)$ & $5 / 48(10)$ & $3 / 22(14)$ \\
\hline
\end{tabular}

Notes: a Twelve patients were sampled on both days. ${ }^{\mathrm{b}} \mathrm{CrCL}_{24 \mathrm{~h}}$ was not available for 4 dosing intervals. ${ }^{\mathrm{C}}$ Unbound concentrations exceeding I (ie, $2 \mathrm{mg} / \mathrm{L}$ ) or 4 times (ie, $8 \mathrm{mg} / \mathrm{L}$ ) the minimal inhibitory concentration throughout the whole dosing interval.

Abbreviations: APACHE, Acute Physiology and Chronic Health Evaluation; $\mathrm{mCrCl}_{24 \mathrm{~h}}$, measured 24-hour urinary creatinine clearance; eGFR $\mathrm{CKD}_{\text {-EPI, }}$ estimated glomerular filtration rate according to the Chronic Kidney Disease Epidemiology Collaboration equation; ICU, intensive care unit; IQR, interquartile range; $n$, number of patients; SOFA, Sequential Organ Failure Assessment.

attainment - on the late sampling day. The effect of increased meropenem CL on the late sampling day might be relatively small compared to the already increased CL on the early sampling day, and/or it might be partially cancelled by decreased volume of distribution after the initial phase of sepsis.

We developed a two-compartment population PK model that was able to accurately predict meropenem plasma concentrations in patients with preserved or increased renal function. Previously, both one- and twocompartment models have been developed for meropenem in critically ill patients. Most one-compartment models have been developed in patients with prolonged infusion ${ }^{17,20,34}$ and/or sparse sampling. ${ }^{21}$ Hence, it is not surprising that a two-compartmental model best fitted the PK data collected in the present study with rich sampling during intermittent infusion. Interestingly, it should be noted that a recent comparative study confirmed similar predictive performance of (one- and two-compartmental) population PK models developed in patients receiving continuous vs intermittent infusion. ${ }^{17}$

Renal function was found to be the only significant predictor of meropenem PK. This is consistent with the vast majority of previously published population PK models of meropenem in ICU patients. ${ }^{17}$ It has been reported that patients with preserved or increased renal function (ie, 

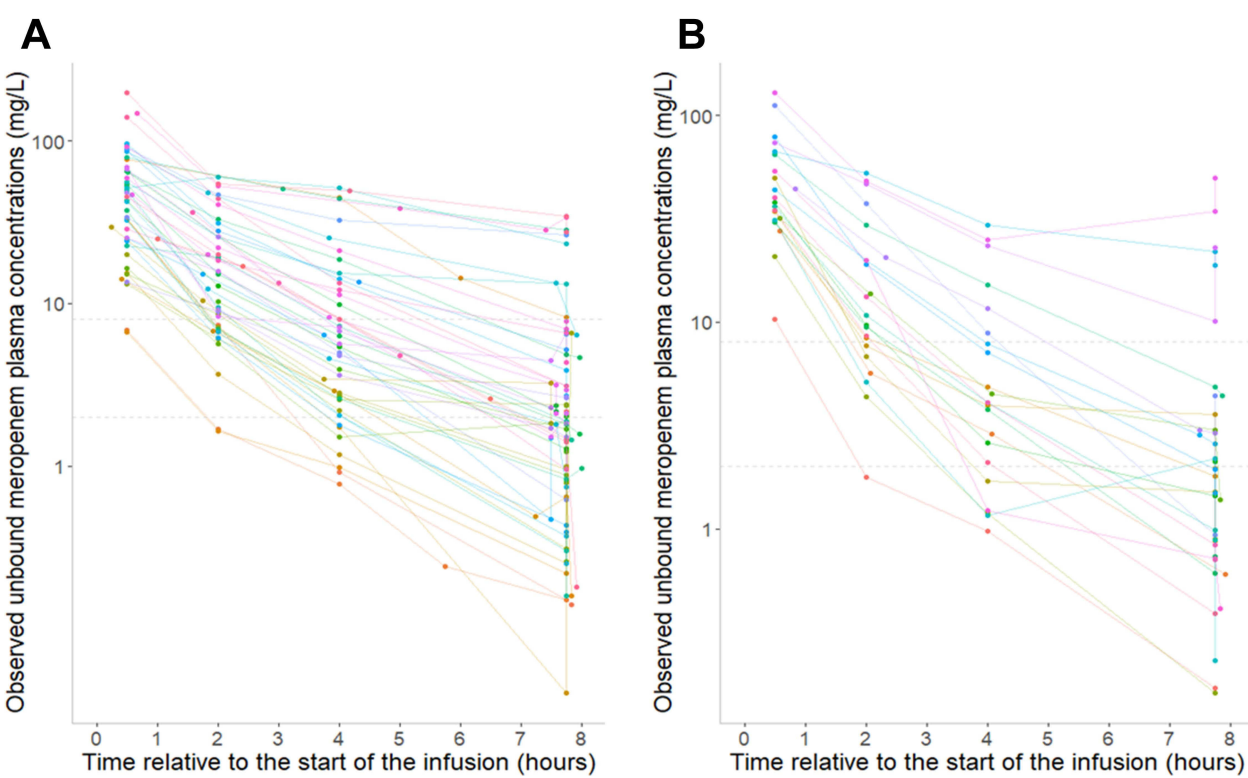

Figure I Observed unbound meropenem plasma concentrations $(\mathrm{mg} / \mathrm{L})$ vs time relative to the start of the infusion (hours). Panel (A) represents the early sampling days, panel (B) represents the late sampling days. The dashed lines represent the $2 \mathrm{mg} / \mathrm{L}$ and $8 \mathrm{mg} / \mathrm{L}$ PK/PD target. The lines connect different observations within the same patient.

ARC) are most at risk of underexposure. ${ }^{35,36}$ This was the initial incentive for this study, ie, to focus only on patients with preserved or increased renal function. Recently, dosing simulations revealed that meropenem dosing according to the drug label is only sufficient for critically ill patients with an $\mathrm{eCrCl}_{\mathrm{CG}}<60 \mathrm{~mL} / \mathrm{min} .{ }^{13}$ Moreover, another simulation study showed that not only extended infusion but also higher meropenem doses were needed to achieve a sufficiently high probability of target attainment when targeting $100 \% f \mathrm{~T}_{>4 \times \mathrm{MIC}}$ considering a minimal inhibitory concentration of $2 \mathrm{mg} / \mathrm{L}$ in critically ill patients with an eGFR $_{\text {CKD-EPI }}>60 \mathrm{~mL} / \mathrm{min}^{21}$ Notwithstanding, many population PK models included a significant proportion of patients with decreased renal function. To date, meropenem population PK modelling was mostly carried out in rather small $^{17}$ or retrospective studies with sparse

Table 2 Population PK Model Parameter Estimates

\begin{tabular}{|c|c|c|}
\hline Parameter & Estimate (\%RSE) (95\% Cl) [\%Shrinkage] & Bootstrap Median $(95 \% \mathrm{Cl})$ \\
\hline \multicolumn{3}{|l|}{ Typical Values } \\
\hline$C L(L / h)$ & $13.7(7.4)(\mid 1.8-15.7)$ & I3.6 (|I.7-|6.I) \\
\hline $\mathrm{V}_{\mathrm{c}}(\mathrm{L})$ & $25.5(8.5)(21.3-29.7)$ & $24.8(19.9-30.4)$ \\
\hline $\mathrm{V}_{\mathrm{p}}(\mathrm{L})$ & $12.4(15.8)(8.6-16.2)$ & $12.7(8.5-19.4)$ \\
\hline$Q(L / h)$ & $8.1(32.6)(2.9-13.3)$ & $8.6(3.5-15.7)$ \\
\hline $\mathrm{eCrCl}_{\mathrm{CG}}$ on $\mathrm{CL}$ & $0.64(20.9)(0.37-0.90)$ & $0.64(0.34-0.90)$ \\
\hline \multicolumn{3}{|l|}{ Interindividual variability } \\
\hline IIV on CL (\%CV) & $57.8(12.2)(44-71.6)[3]$ & $56.8(43-75.9)$ \\
\hline IIV on $V_{c}(\% C V)$ & $57(16.8)(38.2-75.8)[14]$ & $56.6(31.3-78.9)$ \\
\hline IIV on $\mathrm{V}_{\mathrm{p}}(\% \mathrm{CV})$ & $74.4(24.5)(38.6-110.1)[25]$ & $77.2(34.6-146.6)$ \\
\hline Correlation between $C L \& V_{c}$ & 0.185 & $0.178(0.054-0.373)$ \\
\hline \multicolumn{3}{|l|}{ Residual variability } \\
\hline Additive residual variability (mg/L) & $0.147(45.6)(0.1-0.19)[16]$ & $0.155(0.002-0.782)$ \\
\hline Proportional residual variability $(\% \mathrm{CV})$ & $31.1(17.2)(21.34-40.9)[16]$ & $29.1(21.2-39.4)$ \\
\hline
\end{tabular}

Notes: The model dOFV was 1655.702. 1831 out 2000 bootstrap runs (91.5\%) were successful. The condition number was 99.74

Abbreviations: $\mathrm{Cl}$, confidence interval; $\mathrm{CL}$, clearance; $\mathrm{CV}$, coefficient of variation calculated as $\sqrt{\exp \left(\omega^{2}\right)-1} \times 100 \%$; eCrCl $\mathrm{CG}$, creatinine clearance according to the Cockcroft-Gault equation; interindividual variability; $\mathrm{Q}$, Intercompartmental clearance; RSE, root mean square error; $\mathrm{V}_{\mathrm{c}}$, volume of the central compartment; $\mathrm{V}_{\mathrm{p}}$, volume of the peripheral compartment. 


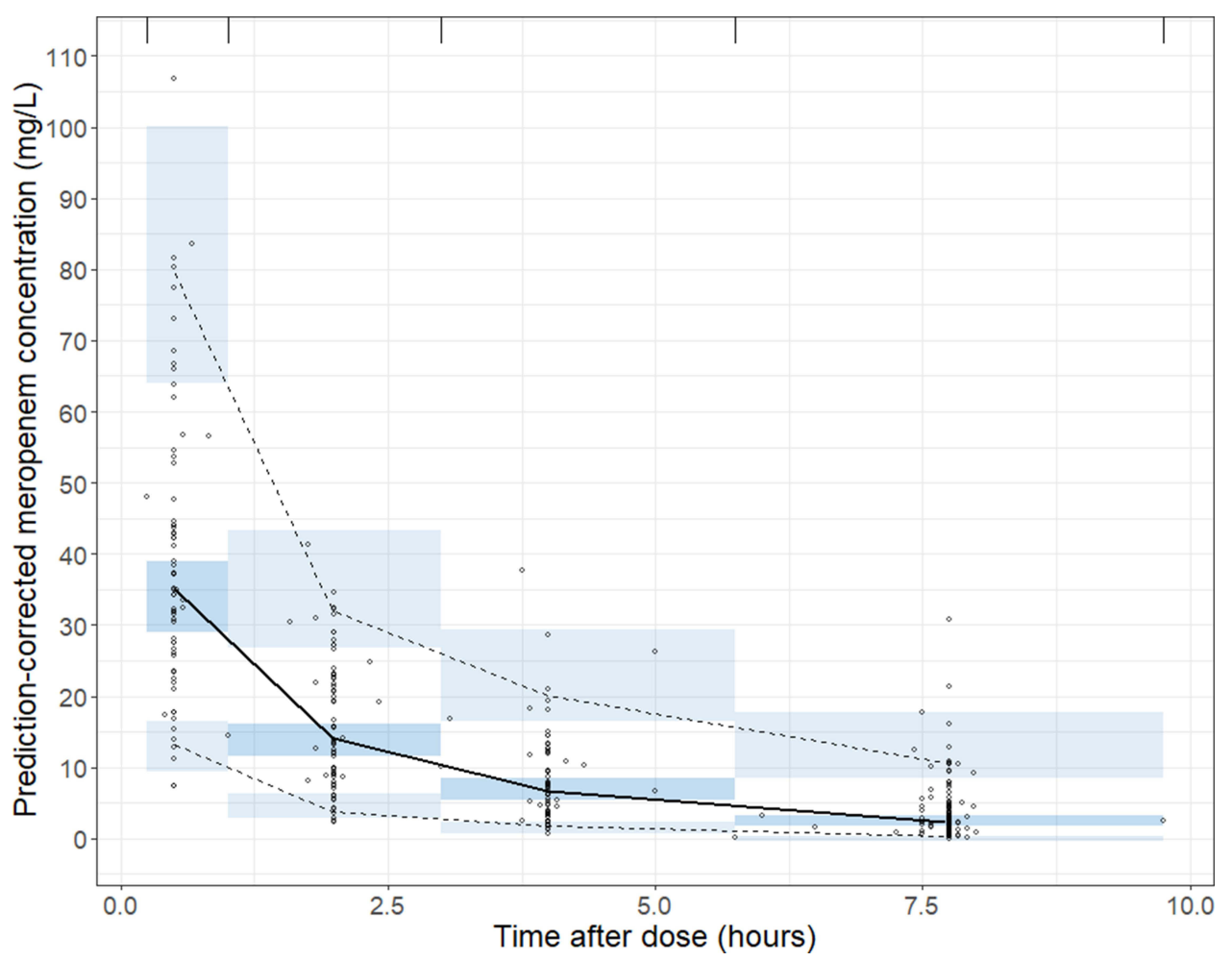

Figure 2 Prediction-corrected visual predictive check of the final model. The observed prediction-corrected meropenem concentrations are represented by circles. The black solid and dashed lines represent median and 2.5th and 97.5 th percentile of the prediction-corrected observations, respectively. The shaded areas indicate $95 \%$ prediction-intervals of the median and 2.5 th and 97.5 th percentile of the simulated values.

sampling. ${ }^{20,21}$ The largest prospective meropenem population PK study to date only included a minority of patients with preserved renal function $\left(32 \%\right.$ had an $\mathrm{eCrCl}_{\mathrm{CG}}$ $>60 \mathrm{~mL} / \mathrm{min}) .^{13}$ In the latter, only $11 \%$ of all patients showed ARC (defined as eCrCl $\mathrm{CG}_{\mathrm{C}} \geq 130 \mathrm{~mL} / \mathrm{min}$ ), whereas ARC was present during $24 \%$ of the dosing intervals in the present study. In the present study, overall median $\mathrm{mCrCl}_{24 \mathrm{~h}}$ was $88 \mathrm{~mL} / \mathrm{min} / 1.73 \mathrm{~m}^{2}$. This is much higher than renal function values reported in the abovementioned population PK studies. Hence, the present population PK model is a valuable addition to existing meropenem population PK models. The present population PK model can be used in future studies to evaluate dose optimization strategies for meropenem in critically ill patients with preserved or increased renal function.

In the present study, the median population estimated meropenem $\mathrm{CL}$ was $13.7 \mathrm{~L} / \mathrm{h}$, which is higher than in several of the previously developed population PK models. ${ }^{13,17,20,21,37}$ On the other hand, a few smaller prospective PK studies have also reported high meropenem CL values similar to the $\mathrm{CL}$ observed in the present study. ${ }^{35,38,39}$ Measured or estimated $\mathrm{CrCl}$ in these studies was similar to the $\mathrm{mCrCl}_{24 \mathrm{~h}}$ in the current study population.
Hence, it is not surprising that we found high meropenem $\mathrm{CL}$ values. This is a direct consequence of the exclusion criteria applied in the present study. For meropenem CL, despite the inclusion of renal function in the population PK model, IIV is still large. This is in accordance with findings from Dhaese et al. ${ }^{17}$ In their comparative study, they found that differences in renal function in the original dataset used to develop the population PK model do not fully explain the variability in their predictive performance. No other covariate mentioned to potentially influence meropenem PK (eg, Sequential Organ Failure Assessment score, Acute Physiology and Chronic Health Evaluation II score, age, body weight) has been identified consistently in population PK studies. Accordingly, we did not retain any of these covariates in our population PK analysis.

This study has several strengths. First, this is the largest prospective PK study with rich sampling in patients with preserved or increased renal function. This study allows a detailed description of meropenem PK in patients most at risk for underexposure and critical evaluation of previously published models. Second, $\mathrm{mCrCl}_{24 \mathrm{~h}}$ was collected in most patients (66/70 dosing intervals). The $\mathrm{mCrCl}_{24 \mathrm{~h}}$ is considered to be the pragmatic gold standard 
in the ICU to monitor renal function. ${ }^{40}$ Nonetheless, $\mathrm{eCrCl}_{\mathrm{CG}}$ was found to be the best predictor of the current model. This could be due to the fact that $\mathrm{mCrCl}_{24 \mathrm{~h}}$ was missing for eight dosing intervals, which were imputed with the median $\mathrm{mCrCl}_{24 \mathrm{~h}}$. A similar finding was observed in the population PK study of Dhaese et al, who retained $\mathrm{eCrCl}_{\mathrm{CG}}$ as significant predictor instead of $\mathrm{mCrCl}_{8 \mathrm{~h}} \cdot{ }^{17}$

On the other hand, several limitations also need to be acknowledged. First, minimal inhibitory concentration values were not reported in the present study. Hence, we assessed PK/PD target attainment according to a worst case scenario, using the clinical minimal inhibitory concentration breakpoint for susceptibility of Enterobacterales to meropenem. ${ }^{29}$ This breakpoint is consistent with the epidemiological cut-off (http://www.eucast.org (accessed on 24 March 2021)) and the previously reported $\mathrm{MIC}_{90}$ (90\% of pathogens have an equal or lower minimal inhibitory concentration) of Pseudomonas aeruginosa. ${ }^{13}$ Second, an external validation is lacking. A recent comparative study found substantial variability in the predictive performance of eight population PK models of meropenem. ${ }^{17}$ Nevertheless, awaiting external validation, this study clearly shows the urgent need for dose optimization in critically ill patients with preserved or increased renal function. Third, sample size was limited (ie, 58 patients), although our study represents the largest prospective population PK study of meropenem so far.

\section{Conclusion}

In conclusion, this study provided detailed insight into meropenem PK in critically ill patients with preserved or increased renal function. We observed poor PK/PD target attainment, which reflects the urgent need for dose optimization of meropenem in these patients. Thorough covariate screening using population PK modelling identified only renal function as a significant predictor of meropenem PK. External validation is desirable before implementing dose optimization strategies based on this population PK model.

\section{Abbreviations}

$\mathrm{ARC}$, augmented renal clearance; $\mathrm{eCrCl}_{\mathrm{CG}}$, estimated creatinine clearance according to the Cockcroft-Gault

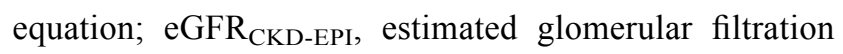
rate according to the Chronic Kidney Disease Epidemiology Collaboration equation; $f \mathrm{~T}_{>1-4 \times \mathrm{MIC}}$, time that the free concentration exceeds 1 to 4 times the minimum inhibitory concentration; ICU, intensive care unit;
$\mathrm{mCrCl}_{24 \mathrm{~h}}$, measured 24-hour urinary creatinine clearance; PK, pharmacokinetic; PK/PD, pharmacokinetic/ pharmacodynamic.

\section{Data Sharing Statement}

The data investigated in this study are available from the corresponding author upon reasonable request.

\section{Ethics Approval and Informed Consent}

The study was conducted in accordance with the Declaration of Helsinki. The present study was approved by the Ethics Committee Research UZ/KU Leuven (S54511). Written informed consent was obtained from the patient or the closest relative before inclusion in this study.

\section{Acknowledgments}

We would like to thank Elien De Mooter and Johan Nicolai for their assistance with the bioanalytical method. We would also like to thank Ine Vercammen, Elien De Mooter, Azuka Chude and Francesca Van Maercke for their assistance in the sample and data collection.

\section{Disclosure}

Erwin Dreesen and Isabel Spriet share senior authorship. BioNotus conducted the bioanalysis in support of this study and received financial compensation for this service. Pieter Annaert is co-founder of BioNotus GCV and is a full time employee of KU Leuven. Joost Wauters reports grants, non-financial support from MSD, grants, other from Gilead, grants, other from Pfizer, outside the submitted work. Erwin Dreesen reports grants from Research Foundation-Flanders (FWO), during the conduct of the study; consultancy fee (paid to the University) from Argenx and Janssen, outside the submitted work. The authors report no other conflicts of interest in this work.

\section{References}

1. Sakr Y, Jaschinski U, Wittebole X, et al. Sepsis in intensive care unit patients: worldwide data from the intensive care over nations audit. Open Forum Infect Dis. 2018;5(12):ofy313. doi:10.1093/ofid/ofy313

2. Singer M, Deutschman CS, Seymour CW, et al. The third international consensus definitions for sepsis and septic shock (Sepsis-3). JAMA. 2016;315(8):801-810. doi:10.1001/jama.2016.0287

3. Rhodes A, Evans LE, Alhazzani W, et al. Surviving sepsis campaign: international guidelines for management of sepsis and septic shock: 2016. Intensive Care Med. 2017;43(3):304-377. doi:10.1007/s00134017-4683-6 
4. Liu VX, Fielding-Singh V, Greene JD, et al. The timing of early antibiotics and hospital mortality in sepsis. Am J Respir Crit Care Med. 2017;196(7):856-863. doi:10.1164/rccm.201609$18480 \mathrm{OC}$

5. Roberts JA, Paul SK, Akova M, et al. DALI: defining antibiotic levels in intensive care unit patients: are current beta-lactam antibiotic doses sufficient for critically ill patients? Clin Infect Dis. 2014;58 (8):1072-1083. doi:10.1093/cid/ciu027

6. Roberts JA, Lipman J. Pharmacokinetic issues for antibiotics in the critically ill patient. Crit Care Med. 2009;37(3):840-851; quiz 859. doi:10.1097/CCM.0b013e3181961bff

7. Taccone FS, Laterre PF, Dugernier T, et al. Insufficient beta-lactam concentrations in the early phase of severe sepsis and septic shock. Critical Care. 2010;14(4):R126. doi:10.1186/cc9091

8. Roberts JA, Abdul-Aziz MH, Lipman J, et al. Individualised antibiotic dosing for patients who are critically ill: challenges and potential solutions. Lancet Infect Dis. 2014;14(6):498-509. doi:10.1016/ S1473-3099(14)70036-2

9. Guilhaumou R, Benaboud S, Bennis Y, et al. Optimization of the treatment with beta-lactam antibiotics in critically ill patientsguidelines from the French Society of Pharmacology and Therapeutics (Societe Francaise de Pharmacologie et Therapeutique-SFPT) and the French Society of Anaesthesia and Intensive Care Medicine (Societe Francaise d'Anesthesie et Reanimation-SFAR). Critical Care. 2019;23(1):104. doi:10.1186 s13054-019-2378-9

10. Mattoes HM, Kuti JL, Drusano GL, Nicolau DP. Optimizing antimicrobial pharmacodynamics: dosage strategies for meropenem. Clin Ther. 2004;26(8):1187-1198. doi:10.1016/S0149-2918(04)80001-8

11. Abdul-Aziz MH, Alffenaar JC, Bassetti M, et al. Antimicrobial therapeutic drug monitoring in critically ill adult patients: a Position Paper. Intensive Care Med. 2020;46(6):1127-1153. doi:10.1007/ s00134-020-06050-1

12. Ehmann L, Zoller M, Minichmayr IK, et al. Role of renal function in risk assessment of target non-attainment after standard dosing of meropenem in critically ill patients: a prospective observational study. Critical Care. 2017;21(1):263. doi:10.1186/s13054-017$1829-4$

13. Burger R, Guidi M, Calpini V, et al. Effect of renal clearance and continuous renal replacement therapy on appropriateness of recommended meropenem dosing regimens in critically ill patients with susceptible life-threatening infections. $J$ Antimicrob Chemother. 2018;73(12):3413-3422. doi:10.1093/jac/dky370

14. Tamatsukuri T, Ohbayashi M, Kohyama N, et al. The exploration of population pharmacokinetic model for meropenem in augmented renal clearance and investigation of optimum setting of dose. $J$ Infect Chemother. 2018;24(10):834-840. doi:10.1016/j.jiac.2018.07.007

15. Petersson J, Giske CG, Eliasson E. Standard dosing of piperacillin and meropenem fail to achieve adequate plasma concentrations in ICU patients. Acta Anaesthesiol Scand. 2016;60(10):1425-1436. doi:10.1111/aas. 12808

16. Drusano GL, Hutchison M. The pharmacokinetics of meropenem. Scand J Infect Dis Suppl. 1995;96:11-16.

17. Dhaese SAM, Farkas A, Colin P, et al. Population pharmacokinetics and evaluation of the predictive performance of pharmacokinetic models in critically ill patients receiving continuous infusion meropenem: a comparison of eight pharmacokinetic models. $J$ Antimicrob Chemother. 2019;74(2):432-441. doi:10.1093/jac/dky434

18. Muller AE, Huttner B, Huttner A. Therapeutic drug monitoring of beta-lactams and other antibiotics in the intensive care unit: which agents, which patients and which infections? Drugs. 2018;78 (4):439-451. doi:10.1007/s40265-018-0880-z

19. Tabah A, De Waele J, Lipman J, et al. The ADMIN-ICU survey: a survey on antimicrobial dosing and monitoring in ICUs. $J$ Antimicrob Chemother. 2015;70(9):2671-2677. doi:10.1093/jac/dkv165
20. Minichmayr IK, Roberts JA, Frey OR, Roehr AC, Kloft C, Brinkmann A. Development of a dosing nomogram for continuous-infusion meropenem in critically ill patients based on a validated population pharmacokinetic model. $J$ Antimicrob Chemother. 2018;73(5):1330-1339. doi:10.1093/jac/dkx526

21. Idoate Grijalba AI, Aldaz Pastor A, Marquet P, Woillard JB. Evaluation of a non-parametric modelling for meropenem in critically ill patients using Monte Carlo simulation. Eur J Clin Pharmacol. 2019;75(10):1405-1414. doi:10.1007/s00228-019-02716-y

22. Dellinger RP, Levy MM, Rhodes A, et al. Surviving Sepsis Campaign: international guidelines for management of severe sepsis and septic shock, 2012. Intensive Care Med. 2013;39(2):165-228. doi:10.1007/s00134-012-2769-8

23. Levy MM, Fink MP, Marshall JC, et al. 2001 SCCM/ESICM/ACCP/ ATS/SIS International Sepsis Definitions Conference. Crit Care Med. 2003;31(4):1250-1256. doi:10.1097/01.CCM.0000050454.01978.3B

24. Bilbao-Meseguer I, Rodriguez-Gascon A, Barrasa H, Isla A, Solinis MA. Augmented renal clearance in critically ill patients: a systematic review. Clin Pharmacokinet. 2018;57(9):1107-1121. doi:10.1007/s40262-018-0636-7

25. Gijsen M, Dreesen E, Annaert P, et al. Meropenem pharmacokinetics and target attainment in critically ill patients are not affected by extracorporeal membrane oxygenation: a matched cohort analysis. Microorganisms. 2021;9(6):1310. doi:10.3390/ microorganisms 9061310

26. Mortensen JS, Jensen BP, Zhang M, Doogue M. Preanalytical stability of piperacillin, tazobactam, meropenem, and ceftazidime in plasma and whole blood using liquid chromatography-tandem mass spectrometry. Ther Drug Monit. 2019;41(4):538-543. doi:10.1097/ FTD.000000000000650

27. Colin P, De Bock L, T'Jollyn H, Boussery K, Van Bocxlaer J. Development and validation of a fast and uniform approach to quantify beta-lactam antibiotics in human plasma by solid phase extraction-liquid chromatography-electrospray-tandem mass spectrometry. Talanta. 2013;103:285-293. doi:10.1016/j.talanta. 2012.10.046

28. Gijsen M, Filtjens B, Annaert P, et al. Meropenem stability in human plasma at -20 degrees $\mathrm{C}$ : detailed assessment of degradation. Antibiotics. 2021;10(4):449.

29. European Committee on Antimicrobial Susceptibility Testing. Testing Breakpoint tables for interpretation of MICs and zone diameters; 2020. Accessed on March 24, 2021.

30. Gijsen M, Huang CY, Flechet M, et al. Development and external validation of an online clinical prediction model for augmented renal clearance in adult mixed critically ill patients: the augmented renal clearance predictor. Crit Care Med. 2020;48(12):e1260-e1268. doi:10.1097/CCM.0000000000004667

31. Wickham H, Averick M, Bryan J, et al. Welcome to the Tidyverse. J Open Source Softw. 2019;4(43):1686. doi:10.21105/joss.01686

32. Wickham H. Ggplot2: Elegant Graphics for Data Analysis. New York: Springer-Verlag; 2016.

33. Goncalves-Pereira J, Silva NE, Mateus A, Pinho C, Povoa P. Assessment of pharmacokinetic changes of meropenem during therapy in septic critically ill patients. BMC Pharmacol Toxicol. 2014;15:21. doi:10.1186/2050-6511-15-21

34. Mattioli F, Fucile C, Del Bono V, et al. Population pharmacokinetics and probability of target attainment of meropenem in critically ill patients. Eur J Clin Pharmacol. 2016;72(7):839-848. doi:10.1007/ s00228-016-2053-x

35. Roberts JA, Kirkpatrick CM, Roberts MS, Robertson TA, Dalley AJ, Lipman J. Meropenem dosing in critically ill patients with sepsis and without renal dysfunction: intermittent bolus versus continuous administration? Monte Carlo dosing simulations and subcutaneous tissue distribution. J Antimicrob Chemother. 2009;64(1):142-150. doi:10.1093/jac/dkp139 
36. Crandon JL, Ariano RE, Zelenitsky SA, Nicasio AM, Kuti JL, Nicolau DP. Optimization of meropenem dosage in the critically ill population based on renal function. Intensive Care Med. 2011;37 (4):632-638. doi:10.1007/s00134-010-2105-0

37. Sjovall F, Alobaid AS, Wallis SC, Perner A, Lipman J, Roberts JA. Maximally effective dosing regimens of meropenem in patients with septic shock. J Antimicrob Chemother. 2018;73(1):191-198. doi: $10.1093 / \mathrm{jac} / \mathrm{dkx} 330$

38. Alobaid AS, Wallis SC, Jarrett P, et al. Effect of obesity on the population pharmacokinetics of meropenem in critically ill patients. Antimicrob Agents Chemother. 2016;60(8):4577-4584. doi:10.1128/ AAC.00531-16
39. Tsai D, Stewart P, Goud R, et al. Optimising meropenem dosing in critically ill Australian Indigenous patients with severe sepsis. Int $J$ Antimicrob Agents. 2016;48(5):542-546. doi:10.1016/j. ijantimicag.2016.08.015

40. Carlier M, Dumoulin A, Janssen A, et al. Comparison of different equations to assess glomerular filtration in critically ill patients. Intensive Care Med. 2015;41(3):427-435. doi:10.1007/s00134-014$3641-9$

\section{Publish your work in this journal}

Infection and Drug Resistance is an international, peer-reviewed openaccess journal that focuses on the optimal treatment of infection (bacterial, fungal and viral) and the development and institution of preventive strategies to minimize the development and spread of resistance. The journal is specifically concerned with the epidemiology of antibiotic resistance and the mechanisms of resistance development and diffusion in both hospitals and the community. The manuscript management system is completely online and includes a very quick and fair peerreview system, which is all easy to use. Visit http://www.dovepress.com/ testimonials.php to read real quotes from published authors. 